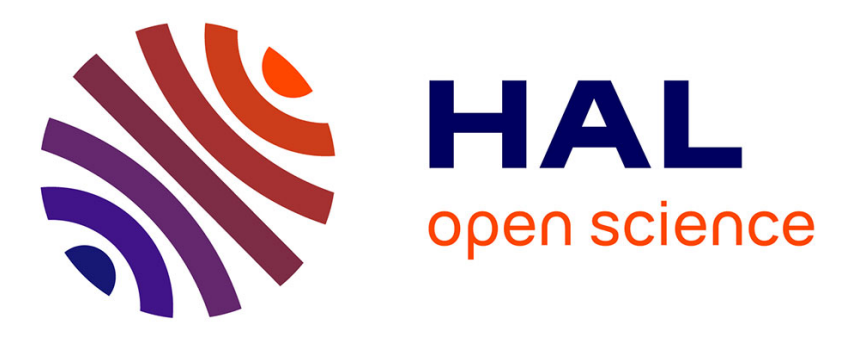

\title{
Extending Value in Legacy Production Systems: Insights from the Liquid Food Processing
}

Brendan P. Sullivan, Monica Rossi, David Ward, Carlo Leardi

\section{To cite this version:}

Brendan P. Sullivan, Monica Rossi, David Ward, Carlo Leardi. Extending Value in Legacy Production Systems: Insights from the Liquid Food Processing. 22nd Working Conference on Virtual Enterprises (PRO-VE 2021), Nov 2021, Saint-Etienne, France. pp.778-788, 10.1007/978-3-030-85969-

5_74. emse- 03350350

\section{HAL Id: emse-03350350 \\ https://hal-emse.ccsd.cnrs.fr/emse-03350350}

Submitted on 25 Nov 2021

HAL is a multi-disciplinary open access archive for the deposit and dissemination of scientific research documents, whether they are published or not. The documents may come from teaching and research institutions in France or abroad, or from public or private research centers.
L'archive ouverte pluridisciplinaire HAL, est destinée au dépôt et à la diffusion de documents scientifiques de niveau recherche, publiés ou non, émanant des établissements d'enseignement et de recherche français ou étrangers, des laboratoires publics ou privés. 
Sullivan B.P., Rossi M., Ward D., Leardi C. (2021) Extending Value in Legacy Production Systems: Insights from the Liquid Food Processing. In: Camarinha-Matos L.M., Boucher X., Afsarmanesh H. (eds) Smart and Sustainable Collaborative Networks 4.0. PRO-VE 2021. IFIP Advances in Information and Communication Technology, vol 629. Springer, Cham. https://doi.org/10.1007/978-3-030-85969-5_74

\title{
Extending Value in Legacy Production Systems: Insights from the Liquid Food Processing
}

\author{
Brendan P. Sullivan ${ }^{1}$, Monica Rossi ${ }^{1}$, David Ward ${ }^{2}$, Carlo Leardi ${ }^{3}$ \\ ${ }^{1}$ Politecnico di Milano, Department of Management and Industrial Engineering, via \\ Lambruschini 4/B, Milan 20156, Italy \\ ${ }^{2}$ TMC Italy, Viale dell'Innovazione, 3, 20126 Milan, Italy \\ ${ }^{3}$ Tetra Pak Packaging Solutions spa, D\&E, Via delfini, 1, 41123, Modena, Italy
}

\begin{abstract}
Shifts in needs coupled with dynamic markets and technological evolution, requires that products and production infrastructures be capable providing extended value for stakeholders throughout the comprehensive systems life cycle. Product change not only reflects shifts in externalities but also on the legacy manufacturing system that produce it. In such situations where product and production change occur it is critical to actively plan and integrate unique system characteristics that can leverage different change types. This requires consideration of not only the changes needed for the product, but also the relational changes of the manufacturing infrastructure. This research provides a basis to support extended value delivery for legacy systems through a conceptual framework based on literature and a use case that evaluates the types and intensity of specific change states according to existing product and production system specifications. The findings from the food processing industry case suggest that knowledge, enabled via smart collaborative networks, and change histories can be effectively used to increase and extend the value of both products and production systems when subject to dynamic changes.
\end{abstract}

Keywords: Changeability, ilities, extended value, life cycle, production systems, systems engineering, food production, industrial case, conceptual framework

\section{Introduction}

New and novel systems continue to be requested including those in manufacturing. However, similar to software development where systems are updated or re-developed through the use of existing system, manufacturing systems are frequently built out of an existing architecture that has in some form been previously deployed [1]. The leveraging of systems to meet new stakeholder needs arises from system complexity and the high development costs associated with creating a completely new solution [1]. By leveraging knowledge derived from legacy systems it is possible to evaluate 
functionalities, reducing costs of change, production down-time, maintenance costs, retraining of employees, un-needed capabilities and undesirable perpetrations [2, 3].

Changeability as a high-level system -ility (flexibility, agility, adaptability, robustness, reconfigurability) is one of the possible solutions that can be applied to extend the value of systems, reducing the time and cost for making changes and improving how system functions are delivered [4-6]. The ability to leverage change for extended value enables legacy systems to be more efficient at adapting to changes that emerge from a variety of sources (shifts in requirements, stakeholder needs, and system functions). To accommodate this, an active and coordinated strategy is required, and while it is not possible to generalize the level of changeability for every system, it is possible to analyze the number of changes the system can easily make (cost vs. time) and the value implications of the suitable changes [7, 8].

The objective of this paper is to provide a literature-based framework, to support the extended value for legacy systems. The paper proposes an approach to support the extension of legacy system value as well as discusses how different types of change can affect the production systems based on an applied use case. The article is structured as follows: Section II discusses the elements of changeability and implications for legacy production systems. Then, Section III presents an approach for extending the value of legacy systems in the liquid food processing sector that is implemented through a case study, which is described in Section IV. Section V concludes the article.

\section{Changeability and Legacy Production Systems}

Changeability represents the modification of systems in anticipation of, or in response to, changes in exogenous variables [9]. In respect to legacy systems this includes extending value throughout a systems life cycle, where the incurrence of change should extend the value of the system in an active manner. This requires distinct contextual and operational knowledge, increasing the complexity of the decision process by requiring an agent to initiate changes that allow for the system to maintain a value throughout its life [10]. In analyzing such systems, it is possible to evaluate change options that reflect on the total number of potential changes the system can make (topdown), or the magnitude of a specific change according to its utility value.

\subsection{Ilities and Changeability Elements}

"Ilities" are grounded in strategic thinking and decision theory and refers to the theoretical and applied notion of change within systems [11]. Changeability represents a high-level system ility that is characterized by the ability of a system to change form, function, or operation, through lower level ilities such as flexibility, agility, adaptability, evolvability, reconfigurability, versatility, and robustness. A change can be understood as any transition of the system from one state to another [12]. Changeability determines what changes, but also how the change occurs and the effect the change has on the system throughout its life cycle [4, 5, 7, 13-17].

Engineering "change" accounts for some of the largest resource intensive processes in engineering design [18] and through the utilization of "ilities" within systems this 
can be reduced. Regardless of the change, intentional/unintentional stakeholders desire for systems to effectively perform and deliver value (Mekdeci et al., 2012).

While changeability is traditionally viewed as a design decision to enable the change of a system, when applied to the evaluation of legacy systems the real options for modification become the focal point. This transitional view of the concept derives from the fact that even the most experienced engineer/team cannot predict all foreseeable changes. Within production processes where system of systems (SoS) are prevalent this means that even if a system was designed for change there will be elements of the SoS that affect how the change occurs, the agent responsible, and the change effect [19].

\subsection{Legacy Production Systems}

It can be necessary for legacy systems to change according to a variety of affects including changes in product specifications, volumes, materials and stakeholder needs. Such systems previously developed through past efforts, represent deployed and designed systems that operate as/within a SoS architecture requiring consideration of what's being produced, resource availability, stakeholder expectations, utility value and functionality. Systems that were initially developed to provide some form of value to a stakeholder are through dynamic pressures being required to change. Determining how changes can extend value requires consideration of how they fit into the SoS and the long-term change value according to feasible tradeoffs as illustrated in Table 1 .

Table 1. Techniques to Understand and Analyze Legacy Systems.

\begin{tabular}{|c|c|c|}
\hline Technique & Tools & Legacy Type \\
\hline $\begin{array}{l}\text { Reverse } \\
\text { Engineering }\end{array}$ & $\begin{array}{l}\text { CAM software, NC programs, Solid-modeling } \\
\text { software, Parametric Diagram }\end{array}$ & Deployed \\
\hline Change History & $\begin{array}{l}\text { Design Structure Matrix, Change Prediction } \\
\text { Method, Domain Mapping Matrices }\end{array}$ & Design, Deployed \\
\hline Documentation & Functional Block Diagram, Use Case Diagrams & Design, Deployed \\
\hline Technical Manual & $\begin{array}{l}\text { Requirement Diagram, Functional Block } \\
\text { Diagram, Use Case Diagrams }\end{array}$ & Design, Deployed \\
\hline Generalization & $\begin{array}{l}\text { Functional Block Diagram, Internal Block } \\
\text { Diagram. Use Case Diagrams }\end{array}$ & Design, Deployed \\
\hline Interviewing & Sequence Diagram, Use Case Diagrams & , Deploy \\
\hline Process Modelling & $\begin{array}{l}\text { State Machine diagram, Internal Block Diagram, } \\
\text { Analysis Model }\end{array}$ & Design, Deployed \\
\hline
\end{tabular}

\section{Framework for Extending Legacy System Value}

Manufacturing industries, system products and customer services provide value through their ability to fulfil stakeholders' needs and wants. These needs evolve over time and may diverge from an original system's capabilities. Thus, a system's value to its stakeholders diminishes over time. Some reasons for this decrease include growth in stakeholder wants and technological opportunities, which make an existing system 
seem inadequate. Other reasons are growth in a system's maintenance costs, due to effects such as depreciation and component obsolescence. Still other reasons are changes in the environment, for example new rules and regulations and so forth. As a result, systems have to be periodically upgraded at substantial cost and disruption. Since complete replacement costs are often prohibitive, system adaptability is a valuable characteristic. Current concepts, methods and tools for architecting engineered systems (emanating from engineering disciplines) lack vital business and economic considerations. As a result, most architectures are not easily adaptable to evolving manufacturing needs and product variants [20]. This gap hinders the European industry from delivering updated products/services quickly and cost-effectively, prevents optimal manufacturing performance, and threatens Europe's leading world position. In summary, increasing a system's lifetime value requires improved methods of architecting it.

This framework suggested in this section was developed by leveraging literature and a series of interviews from production and system engineers in the food processing industry to support the management of legacy systems by evaluating the types and intensity of specific change states according to existing product and production system specifications. As illustrated below (Figure 1) this framework represents a basis to advance and support the evaluation of legacy system changeability for the purpose of extended life cycle value, in response to stakeholder needs and dynamic pressures.

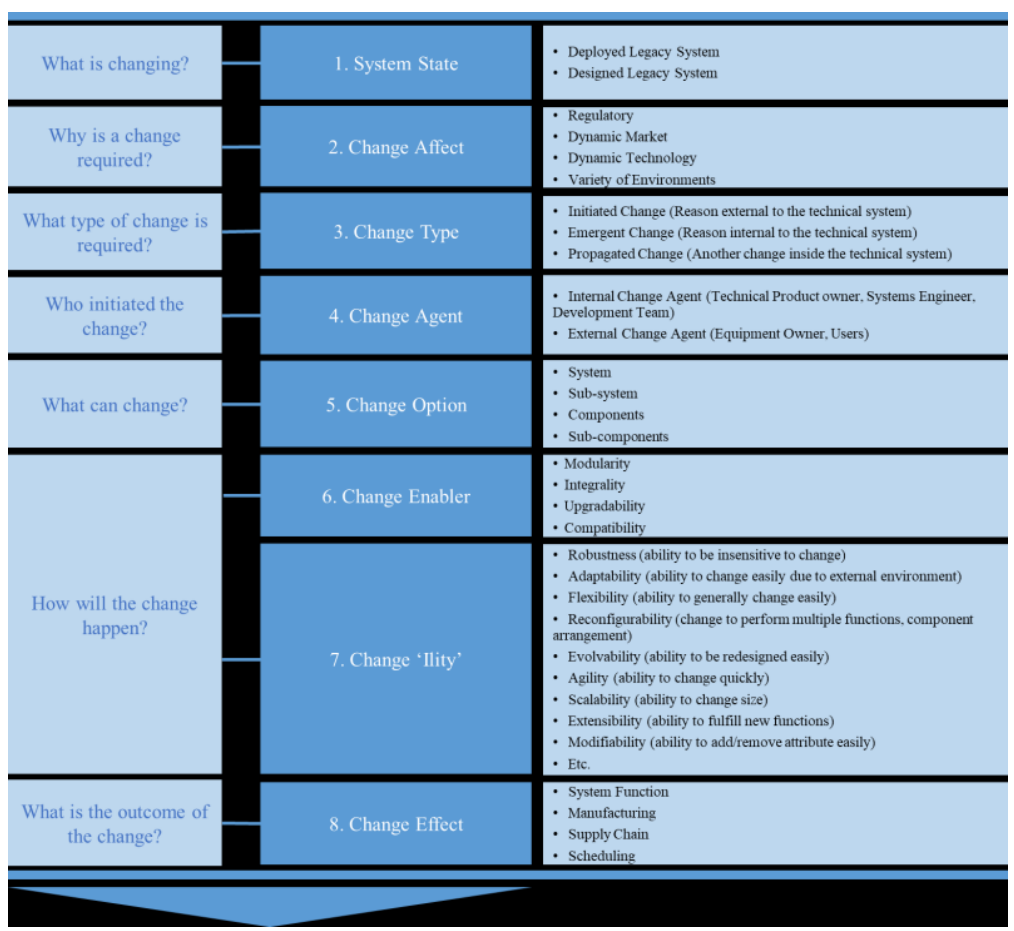

Fig. 1. Conceptual Framework for the Analysis of Changeability within Legacy Systems.

The framework is a question-based framework built around 8 dimensions that characterize changeability in legacy systems, detailed in the following. 
1. System State: In cases where the system being analyzed has been deployed and are highly embedded into daily routines it is difficult to modify and replace the singular sub-systems or components when new technology or other needs must be brought forth. Additionally, refactoring or modernizing any deployed legacy system requires careful analysis of the extent that any change or failure to that system will have. Similarly legacy systems which were previously designed that have not been deployed require these same incidents to be overcome. While modularity and other lower-level ilities have successfully been used, this requires either a complete analysis of how the system can change, or redesign of the entire system. The redesign of the system design may have the greatest long-term value for the manufacturer of the equipment however can be slow and expensive.

2. Change Affect: The inclusion of socio variables has been a regular practice in systems engineering since the 1970's and have been found to be the most critical areas giving rise to system change $[17,21]$.

a. Regulatory based externalities refer to norms set by the standardizing organization, governments, governing bodies, and the organization itself. The laws and regulations are models that require companies to analyze the potential impacts of the system (health, safety, compliance). Regulations can include the Stakeholder security interests like Intellectual Property Rights, Information Assurance, Security Laws, Supply Chain Compliance, and Security Standards.

b. Dynamic Market based externalities are an effect of the new markets are emerging rapidly, while existing markets are changing. Staying ahead of competition requires highly responsive abilities that allow for changes to the system throughout the life cycle of the legacy system.

c. Dynamic Technology based externalities are a response to the development of new technologies that are required to produce the specific product, or at behest of the change agent. Technology changes are necessary to keep a system competitive, meet changing market demands, or requirements for customization, what is partially addressed in Schulz [22].

d. Environment based externalities reflect the level of integration, number of sub-systems and how they are embedded.

3. Change Type: All changes can be seen as both threats and opportunities. On one hand, changes enacted by the agent can increase the amount of rework and can lead to additional changes, thus increasing costs and effort; on the other, they offer the chance to improve the system, increasing the performance, providing useful functionalities or reducing undesired features [23]. The forces representing what the system must respond is categorized on how each change emerges depending on the agent and the decision taken (impact, observation, decision-making).

a. Initiated Change: Can be planned and unplanned changes that are generated by an outside source and are frequently attributed to a change in requirements.

b. Emergent Change: Are "caused by the state of the design, where problems occurring across the whole design and throughout the product life cycle can lead to changes" [24]. 
c. Propagated Change: Undesired changes that come due to other changes having been made to the system.

4. Change Agent: The forces representing what the system must respond to (change for) are presented and acted upon through a distinct agent. The respective change can be either intentional or implied, but always requires the ability to set the necessary change in motion. As shown in [12] the initiator can either be in or out of the technical system. When classifying the respective change agent it is important to consider what is necessary for the decision maker to initiate this change according to the impact, observation and decision-making [12].

5. Change Option: The modelling of features and functions allows for change options to be identified according to the number and magnitude of the changes the system can perform to support value generation. This parameter describes the feasibility of the change, the suitability in respect to value extension and how the change can be facilitated through the subsequent change. The number of potential viable changes the system can afford, magnitude perspective of the change (can be a matrix). Reflecting the most critical changes, and pathway that the system can follow to extend the value of the system.

6. Change Enabler: As a system architecture-type ility, enablers allow for a system to change and are related to the change-type ilities [25]. Affecting the inherent complexity of the system, enablers determine the effectiveness of the change.

7. Change Ility: The ilities for implementing or enacting the change must be compatible with the functions of the system and needs of the stakeholder. Through the evaluation of suitable changes the architecture of the system can go beyond functionalities (reliability, maintainability, etc.), to include life cycle implications. The application here of lower-level ilities as means for change allow the balancing for the number of changes (volume) and value generation.

8. Change Effect: Based on the selected ility the value and utility of the change can be analyzed for the change, the system and the SoS. This can be accomplished through different degrees of abstraction including an impact analysis (new vs old), compliance and regulatory conformance review (when in non-compliance the change is reviewed), and risk analysis (safety, export control).

\section{Industrial Use Case}

Liquid food packaging product lines constitute the assets of a wider eco-system including skill, stakeholders, customers, consumers awareness trends, market needs $[26,27]$. The proposed case regards the cap application, one of the relevant sub-systems in a liquid food packaging line and leverages the framework to evaluate and support successful system changeability. Through this, the function of the sub-system (to apply pre-manufactured caps on packages) will be changed to allow for the opening and reclosing function. According to the recent Single-Use Plastics (SUP) EU directive, the caps are expected not to be detached from the package due to growing environmental safe-guard expectations. The architectural and functional impact on the installed packaging lines, alias the legacy systems, is relevant and classified according to the framework (Section 3) in Table 2 below. 
Table 2. Analysis of Changeability within Industrial Use Case Legacy System.

\begin{tabular}{ll}
\hline Changeability Criteria & Legacy System State \\
\hline System State & Designed \\
Change Affect & Regulatory, Dynamic Market \\
Change Type & Initiated Change \\
Change Agent & Internal Change Agent \\
Change Option & Sub-system \\
Change Enabler & Modularity \\
Change Ility & Flexibility and Robustness \\
Change Effect & System Function \\
\hline
\end{tabular}

The change enabler, modularity was implemented due to afforded autonomy and ability for non-hierarchical integration [28]. As commonly utilized it satisfies the needs of the change-ilities (flexibility and robustness) allowing for distinct system elements to be developed/changed and supporting the management of the increased technological complexity and interface requirements.

The first implementations relate about legacy systems where the independence assumption was only partly satisfied. The major negative effect was setting-up the interface requirements as a no-one land for fights among conflictual engineering silos. In the case, although limited, the results are being evaluated to determine the utility for each respective change. The time for change implementation was sensibly reduced but the production system life cycle was not guaranteed in long terms due dynamic change affects. This approach identifies and limits the cooperation to the module suppliers, developer and integrator and operational environment. Smart and cooperative networks were not explicitly needed or addressing significant value increase.

Through the consideration of robustness and flexibility it is possible to set higher quality standards, noise-insensitive, growing capacities able to be updated without impacting the overall asset and operational costs. The solutions developed under these concepts are still effectively operating in the market. The efficiency though is limited to the original requirements of the system and are difficult to overcome without incorporating additional change enablers that will further reduce development cost and extend the potential of the respective change options being implemented.

The main misconception of the case related to the limited number of available changes, and the direct level of application. Robustness at the component or sub-system level was often confused with robustness verification at system level with limited opportunities to really implement insensitiveness to noises. Flexibility was partially accomplished, however due to the lack of a consistent architecture and functional description real change options and the subsequent change effects were minimized. Fundamentally a rigorous and wise application of changeability and systems engineering principles is still missing in the liquid food packaging industry and will require the development of additional tools to improve the analysis. However, great benefits came from its introduction. Once again, despite an enlarged stakeholder chain, the collaborative aspect was still reduced and the mutual learning deriving from smart, culturally nonhomogeneous, partnerships improved. 


\subsection{Evolution}

The aim was to pass from specific to general changeability through two change-ilities. As discussed throughout this paper and illustrated in Table 3, this means that the system is developed to comply with expected future needs. Unlike the conventional design process in which a system is designed for a nominal set of requirements, it is developed to be adapted to different or additional functions beyond their normal operational mode based on forecast information. In the pilot case quantitative estimations were calculated through Monte Carlo applications within the architectural framework through a series of Design Structure Matrices. To quantify the monetary benefit and Expected Net Present Value (ENPV) calculation under uncertainty. The project targets were driven to the following measures Number of Closure Types, Number of Package Types, Damage rate and Noise level as shown in Figure 2.

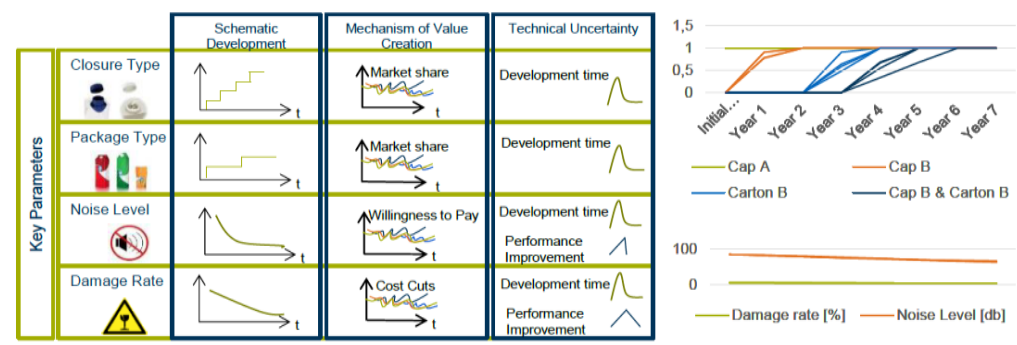

Fig. 2. Overview Technology Forecasting Under Uncertainty.

The implementation of the framework has the potential to better integrate into the mindset of engineers and increasingly complete systems engineering set of systems engineering methodologies and tools. A wider attention is emerging to the socio-human themes likes as consumers acceptance of environmentally sustainable products that unavoidable shall be different from the ones we are used to. The full changeability concept has so to be acquired and its benefits delivered to the overall chain of stakeholders, starting from us, as consumers, and the finite world we are living. Equally new collaborations, heterogeneous environments, contribute to increase the confidence robustness of the system.

\section{Concluding Remarks}

This research provided evidence that value extension of legacy systems, as shown in the industrial case of liquid food packaging, is challenged by the increasing dynamic markets, technological advancements and regulatory acts. A systemic life-cycle thinking is required. The cooperation of several partners: academic, industrial, SW\&HW partners into a smart network is the pre-requisite to framework all the knowledge, empirical, enabling applied methodologies and soft socio-human drivers necessary to understand and successfully drive changeability.

The article is intended as one first step to promote the creation and the characterization of such type of smart and sustainable collaborative networks and will 
be expanded to a more complex system, to provide more substantive results and better evaluation of the change effect cost and value implications.

\section{References}

1. Ross, A.M., Rhodes, D.H.: The system shell as a construct for mitigating the impact of changing contexts by creating opportunities for value robustness. Proc. 1st Annu. 2007 IEEE Syst. Conf. 226-232 (2007). https://doi.org/10.1109/SYSTEMS.2007.374677.

2. Sassanelli, C., Rossi, M., Pezzotta, G., Pacheco, D.A. de J., Terzi, S.: Defining Lean Product Service Systems (PSS) features and research trends through a systematic literature review. Int. J. Prod. Lifecycle Manag. 12, 37-61 (2019). https://doi.org/https://doi.org/http://dx.doi.org/10.1504/IJPLM.2019.104371.

3. Sassanelli, C., Pezzotta, G., Pirola, F., Rossi, M., Terzi, S.: The PSS Design GuRu Methodology: Guidelines and Rules generation to enhance Product Service Systems (PSS) detailed design. J. Des. Res. 17, 125-162 (2019). https://doi.org/https://doi.org/10.1504/JDR.2019.105756.

4. Sullivan, B., Rossi, M., Ramundo, L., Terzi, S.: Characteristics for the implementation of changeability in complex systems. In: XXIII Summer School Francesco Turco 2019. pp. 1-7. , Brescia, Italy (2019).

5. Ross, A.M., Rhodes, D.H.: Architecting systems for value robustness: Research motivations and progress. 2008 IEEE Int. Syst. Conf. Proceedings, SysCon 2008. 216223 (2008). https://doi.org/10.1109/SYSTEMS.2008.4519011.

6. Ricci, N., Rhodes, D.H., Ross, A.M., Fitzgerald, M.E.: Considering alternative strategies for value sustainment in systems-of-systems. SysCon $2013-7$ th Annu. IEEE Int. Syst. Conf. Proc. 725-730 (2013). https://doi.org/10.1109/SysCon.2013.6549963.

7. Sullivan, B.P., Rossi, M., Terzi, S.: A Review of Changeability in Complex Engineering Systems. In: IFAC-PapersOnLine. pp. 1567-1572 (2018). https://doi.org/10.1016/j.ifacol.2018.08.273.

8. Rehn, C.F., Pettersen, S.S., Garcia, J.J., Brett, P.O., Erikstad, S.O., Asbjørnslett, B.E., Ross, A.M., Rhodes, D.H.: Quantification of changeability level for engineering systems. Syst. Eng. 22, 80-94 (2019). https://doi.org/10.1002/sys.21472.

9. Fitzgerald, M.E., Ross, A.M.: Sustaining lifecycle value: Valuable changeability analysis with era simulation. SysCon 2012 - 2012 IEEE Int. Syst. Conf. Proc. 202-208 (2012). https://doi.org/10.1109/SysCon.2012.6189465.

10. Ross, A.M., Rhodes, D.H.: Using Natural Value-Centric Time Scales for Conceptualizing System Timelines through Epoch-Era Analysis. Incose. 15 (2008). https://doi.org/10.1002/j.2334-5837.2008.tb00871.x.

11. Colombo, E.F., Cascini, G., de Weck, O.L.: Classification of Change-Related Ilities Based on a Literature Review of Engineering Changes. J. Integr. Des. Process Sci. 20, 1-21 (2016). https://doi.org/10.3233/jid-2016-0019.

12. Ross, A.M., Rhodes, D.H., Hastings, D.E.: Defining Changeability: Reconciling Flexibility, Adaptability, Scalability, Modifiability, and Robustness for Maintaining System Lifecycle Value. Syst. Eng. 11, 246-262 (2008). https://doi.org/10.1002/sys.

13. McManus, H., Richards, M.G., Ross, A.M., Hastings, D.E.: A Framework for Incorporating "ilities" in Tradespace Studies. Am. Inst. Aeronaut. Astronaut. 1-14 (2007). https://doi.org/10.2514/6.2007-6100.

14. Altenhofen, J.A., Oyama, K.F., Jacques, D.R.: A methodology to determine the influence of requirements change to support system design. IIE Annu. Conf. Expo 2015. 2181-2190 (2015). 
15. Beesemyer, J.C., Ross, A.M., Rhodes, D.H.: An empirical investigation of system changes to frame links between design decisions and ilities. Procedia Comput. Sci. 8, 31-38 (2012). https://doi.org/10.1016/j.procs.2012.01.010.

16. Colombo, E.F., Cascini, G., De Weck, O.L.: Classification of Change-Related Ilities Based on a Literature Review of Engineering Changes. J. Integr. Des. Process Sci. 20, 3-23 (2016). https://doi.org/10.3233/jid-2016-0019.

17. Fricke, E., Schulz, A.P.: Design for changeability (DfC): Principles to enable changes in systems throughout their entire lifecycle. Syst. Eng. 8, 342-359 (2005). https://doi.org/10.1002/sys.20039.

18. Eckert, C.M., Clarkson, P.J., Zanker, W.: Change and customisation in complex engineering domains. Res. Eng. Des. 15, 1-21 (2004). https://doi.org/10.1007/s00163003-0031-7.

19. Rhodes, D.H., Ross, A.M.: Five aspects of engineering complex systems: Emerging constructs and methods. In: 2010 IEEE International Systems Conference Proceedings, SysCon 2010. pp. 190-195 (2010). https://doi.org/10.1109/SYSTEMS.2010.5482431.

20. Elmaraghy, H.A.: Changing and Evolving Products and Systems - Models and Enablers. In: Changeable and Reconfigurable Manufacturing Systems. pp. 25-45 (2009).

21. Mehrabi, M.G., Ulsoy, A.G., Koren, Y.: Reconfigurable manufacturing systems: key to future manufacturing. J. Intell. Manuf. 11, 403-419 (2000). https://doi.org/10.1023/A:1008930403506.

22. Schulz, A.P., Fricke, E.: Incorporating flexibility, agility, robustness, and adaptability within the design of integrated systems - key to success? Gatew. to New Millenn. 18th Digit. Avion. Syst. Conf. Proc. (Cat. No.99CH37033). 1/17 pp. v, 1-8 (1999). https://doi.org/10.1109/DASC.1999.863677.

23. Jarratt, T.A.W., Eckert, C.M., Caldwell, N.H.M., Clarkson, P.J.: Engineering change: An overview and perspective on the literature. Res. Eng. Des. 22, 103-124 (2011). https://doi.org/10.1007/s00163-010-0097-y.

24. Ross, A.M., Rhodes, D.H.: Using attribute classes to uncover latent value during conceptual systems design. 2008 IEEE Int. Syst. Conf. Proceedings, SysCon 2008. 714 (2008). https://doi.org/10.1109/SYSTEMS.2008.4518981.

25. Ross, A.M., Rhodes, D.H.: Towards a prescriptive semantic basis for change-type ilities. $\begin{array}{lllll}\text { Procedia } & \text { Comput. } & \text { Sci. 44, 443-453 }\end{array}$ https://doi.org/10.1016/j.procs.2015.03.040.

26. Sassanelli, C., Da Costa Fernandes, S., Rozenfeld, H., Mascarenhas, J., Terzi, S.: Enhancing knowledge management in the PSS detailed design: a case study in a food and bakery machinery company. Concurr. Eng. Res. Appl. (2021). https://doi.org/10.1177/1063293X21991806.

27. Pinna, C., Galati, F., Rossi, M., Saidy, C., Harik, R., Terzi, S.: Effect of product lifecycle management on new product development performances: Evidence from the food

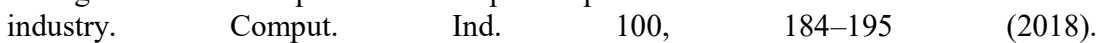
https://doi.org/10.1016/j.compind.2018.03.036.

28. Boucher, X., Cerqueus, A., Delorme, X., Gonnermann, C., Paul, M., Reinhart, G., Schulz, J., Sippl, F.: Towards Reconfigurable Digitalized and Servitized Manufacturing Systems: Conceptual Framework. IFIP Adv. Inf. Commun. Technol. 566, 214-222 (2019). https://doi.org/10.1007/978-3-030-30000-5_28. 